Marquette University

e-Publications@Marquette

College of Nursing Faculty Research and

Publications

Nursing, College of

5-11-2006

\title{
Recommendations for Sexuality Education for Early Adolescents
}

Kristin Haglund

Marquette University, kristin.haglund@marquette.edu

Accepted version. Journal of Obstetric, Gynecologic, \& Neonatal Nursing, Vol. 35, No. 3 (May/June 2006): 369-375. DOI. (C) 2006 Blackwell Publishing. Used with permission. 


\section{Recommendations for Sexuality Education for Early Adolescents}

By Kristin Haglund

Objective: To determine community support and identify appropriate learning methodologies, parameters of delivery, and intervention content. Design: Qualitative descriptive study in which participants were interviewed in a semistructured format. Data were analyzed thematically. Setting: An urban pediatric primary care clinic from which youths and parents were recruited. Participants: Ten youths, 10 parents, and 10 community members. Community members included professional and laypersons who had experience in working with early adolescents or in working with children of any age on sexuality issues. Overall, most participants were female (67\%) and African American (67\%). Results: Descriptions of early adolescents ' knowledge of sexuality, participants 'support for sexuality education for early adolescents, recommendations for education content, and preferred methods for education delivery. Conclusion: The participants supported comprehensive sexuality education for early adolescents. They believed that it would help youths to be abstinent, would provide some protection from sexual abuse, and would prepare them to practice safer sex in the future.

Early adolescence is a period of transition, including for some, to initiation of sexual activity. A wide range for rate of coitarche by the end of middle school has been reported including $6 \%$ to $45 \%$ of students (Aten, Siegel, Enaharo, \& Auinger, 2002; Blake, Simkin, Ledsky, Perkins, \& Calabrese, 2001; Jemmott, Jemmott, \& Fong, 1998; Kirby, Korpi, Adivi, \& Weissman, 1997; Kirby, Korpi, Barth, \& Cagampang, 1997; Tiezzi, Lipshutz, Wrobleski, Vaughan, \& McCarthy, 1997). Coitarche varied by gender with males reporting higher rates than females (Aten et al., 2002; Grunbaum et al., 2004; Kirby, Korpi, Adivi et al., 1997; Tiezzi et al., 1997). For studies in which the sample was predominantly African American (Aten et al.; Jemmott et al., 1998), the rate of coitarche was $25 \%$ to $45 \%$, compared to $8 \%$ to $20 \%$ in predominantly Hispanic samples (Kirby, Korpi, Adivi et al.; Kirby, Korpi, Barth et al., 1997; Tiezzi et al.), and 6\% in a study of predominantly White non-Hispanic youths (Blake et al., 2001). Nationwide data reflect a similar pattern by ethnicity with $19 \%$ of African American, $8 \%$ of Hispanic, and $4 \%$ of White youths reporting coitarche before age 13 (Grunbaum et al., 2004).

Engaging in genital sexual activities places one at risk for adverse consequences such as premature pregnancy, early parenting, and sexually transmitted infections (STIs) including HIV. Consequences may be particularly severe for the younger adolescents because of biological, Haglund 1 
psychological, and social vulnerabilities. In 2000, approximately 20,000 teenagers between the ages of 10 and 14 became pregnant. Of these pregnancies, an estimated $14 \%$ ended in miscarriages, $43 \%$ in live births, and $43 \%$ in elective abortions (Ventura, Abma, Mosher, \& Henshaw, 2004). Since 1990, the pregnancy and birth rates for these women have decreased. In 1990, 3.5 per 1000 girls under 15 became pregnant and 1.4 delivered a live infant (Ventura et al., 2004). In 2003, 0.6 per 1000 girls under 15 delivered a live infant (Hamilton, Martin, \& Sutton, 2004).

The reduction in pregnancy rates is encouraging, yet continued efforts toward further reductions are indicated. Pregnancy jeopardizes the health of a young mother and her child. Mothers under 15 had the highest rates of anemia and eclampsia compared to all older mothers and a high rate of pregnancy associated hypertension, 2nd only to mothers who were 45 to 54 years old (Menacker, Martin, MacDorman, \& Ventura, 2004). Infants born to mothers under 15 had the highest rates of prematurity, low birthweight, and infant death compared to all older mothers (Menacker et al., 2004).

In addition to premature pregnancies, 3,000,000 adolescents contract STIs annually (Ozer, Brindis, Millstein, Knopf, \& Irwin, 1997). Immaturity of the cervical os places young female adolescents at increased vulnerability to infections. Between the years 2000 and 2003, 14,669 persons aged 13 to 24 were diagnosed with HIV/AIDS in 32 states (Centers for Disease Control and Prevention, 2004). However, many more young people are infected than are reported each year.

Prevention efforts have been concentrated in school-based programs including abstinence-only and abstinence-plus safer sex programs. There is not yet a program that has demonstrated a consistent, statistically signifi cant effect on delaying the onset of sexual intercourse, yet there is a critical need for one (Kirby, Korpi, Adivi et al., 1997). Interventions to encourage abstinence appear to be most successful with youths who have not yet experienced sexual intercourse (Aarons et al., 2000; Aten et al., 2002; Coyle, Kirby, Marlin, Gomez, \& Gregorich, 2003).

This study was developed as a targeted needs assessment in preparation for a sexuality program designed to encourage sexual abstinence in early adolescents. The aims of this study were to identify the following: (a) community support for a sexuality program designed to encourage abstinence in this age group; (b) effective and preferred learning methodologies for youths in this age group; (c) preferred parameters of program delivery such as time, location, and preferred presenters; and (d) program content.

Haglund 2 


\section{Methodology}

\section{Sampling Strategy}

The sample comprised youths, parents, and community members. Youths and parents were recruited by convenience sampling. The researcher waited at an urban pediatric primary care clinic on select days. She approached families waiting in examination rooms to explain the study. Interested parents or children, or both, were consented that day and interviewed after their visit. As this was an exploratory study, the researcher was interested in the opinions of children who were both within and outside of the targeted age group.

Community members included professionals and laypersons who had experience in working with early adolescents or in working with youths of any age on sexuality issues. Professionals were recruited in a purposive way. The researcher identified experts who were known to her and requested their participation. Some participants identified others who were also asked to participate. For youths, parental or guardian consent and assent for participation were obtained. Informed consent was obtained from all adults. Protection of human subjects approval was obtained from the appropriate boards.

The sample included 30 participants to provide variety in perspectives, yet limit the volume of qualitative data to facilitate analysis. A description of the participants is summarized in Table 1. The youths ranged in age from 8 to 15 years with a mean age of 10.7. For some families, only parents were interviewed and in others only the children, because of participant preferences or attendance at the clinic. Three parent-child dyads, one parent with two children, six parents alone, and five children alone were interviewed. Community members included seven health care providers (a medical assistant, two registered nurses, three advanced practice nurses) and a substance abuse counselor, two teachers (an elementary school science teacher and a secondary teacher from an alternative school), and one informal guardian. All the community members were also parents.

\section{Data Collection}

Data were obtained via audiotaped interviews conducted in a private office or examination room in a semistructured format using an interview guide. The guide, in Table 2 , included questions designed to elicit the participants ' opinions on the support for abstinence interventions, effective learning methodologies, appropriate delivery strategies, and content. The same guide was used with all participants; however, it was not strictly followed. Participants provided some responses that the questions did not address, and the researcher asked spontaneous follow-up Haglund 3 
questions. When interviewing children, the subject of the question was changed from "youths " or "your child " to " you " or " kids your age " or " kids at your school. " Length of interviews varied from 15 to 30 minutes. Each participant received $\$ 10$.

\section{Data Analysis}

Audiotaped interviews were transcribed by a professional transcriptionist. The researcher listened to each interview while reviewing the transcripts to correct errors and omissions and to remove identifiers. Transcriptions were then coded. The researcher conducted all the data analyses. The initial codes (support, methodology, delivery, and content) straightforwardly corresponded to the aims of this study. Eventually, data within each of these large categories were recoded into more specific codes. For example, data within methodology were recoded into the more specific codes of materials, activities, presenters, computers, and logistics. As the researcher worked through the transcripts, new codes also emerged from the data such as sources of sexual information and religious influences. Analysis eventually revealed descriptions of early adolescents' sexuality knowledge, the participants ' support for sexuality education for early adolescents, recommendations for education content, and the preferred methods for education delivery.

\section{Findings}

\section{Early Adolescents' Sexual Knowledge}

All participants believed that early adolescents had heard of sex and had varying degrees of knowledge about it. The primary source for sexuality information reported by youths and adults was from adults in both planned and inadvertent ways. Youths received some accurate, purposeful sexuality education from parents, teachers, and adult leaders in scouts and other youth groups. They received inadvertent education by overhearing adults in their families and communities talking about sex or seeing adults engage in sexual activity in print, film, or real life. They learned from the examples set by the familiar adults in their lives as well as by celebrities in their real and fictitious lives.

Participants from all three groups believed that 10year-olds knew that having sexual intercourse involved the genitals of a boy and a girl. By age 12, most youths knew what intercourse meant. However, their knowledge was believed to be incomplete and not contextual. They might know that menstruation was related to pregnancy without knowing how, and they did not understand how intercourse fit within the context of a relationship.

The youths in this study defined sex as the heterosexual act of a man's penis being Haglund 4 
received into a woman's vagina. One 10-year-old boy described going to parties where "girls dance on the boys" by pushing their buttocks "to the boys private parts." He did not consider this behavior sexual and denied that sex happened at these parties. Watching suggestive music videos or participating in suggestive dancing was appropriate for children their age because they did not show or involve "sex." Although the adults in this study considered the media to be a primary source for (mis)information about sexuality, the youths did not agree. They denied learning about sex on television "because their mothers wouldn't let them watch that," that is, graphic portrayals of sexual intercourse. They reported that they heard messages about abstinence, condoms, and HIV prevention in various media formats. They did not identify the sexual innuendos of television sitcoms or the suggestive clothing and behaviors on music videos as being about sex.

Similarly, youths in this study stated they did not know what the word abstinence meant, although they said that they knew that they were not supposed to have intercourse until they were older. For the adult participants, abstinence meant refraining from any genital and anal contact as well as avoiding risk behaviors and situations that may lead to genital contact. Risk behaviors included romantic kissing, removal of clothing, and touching breasts or genitals whether clothed or unclothed. Suggestive cues and risky situations included wearing provocative clothing, using sexual language, or being alone with a youth of the opposite sex. The adults and youths believed that sexual activity occurred in a progressive way, "kissing leads to fondling, fondling leads to clothes getting off, and that leads to sex." Engaging in certain behaviors may not lead to intercourse right away but Maybe a month later or so [one youth may say to another], well I've been with you for a month now and all we did was hold hands and kiss. Don't you feel like I feel? I love you, you love me and there it is [they will engage in, or at least consider having, sex]." Most participants agreed that holding hands, hugging, and some kissing were appropriate behaviors for teenagers but not for youths under 12 years. Three adults believed that teenagers should not hug and kiss either.

\section{Support for Sexuality Education}

Participants were asked whether they thought it was appropriate to talk to children between the ages of 10 and 12 about having sexual intercourse and being sexually abstinent. Two persons, one youth and one community member (7\%), did not respond to this question. Of those who did, $57 \%(n=17)$ believed that age 10 was appropriate, $27 \%(n=8)$ recommended ages 8 to 9 years, and $10 \%(n=3)$ believed that sexuality education outside of the home should Haglund 5 
begin at age 12. The last comprised two community members and one parent. They agreed that adults should answer the questions of children under 12 but should wait until they reached age 12 to teach them about sexual intercourse.

Parents recommended that sexuality education should begin in the home, " the earlier the better. "Participants from all groups believed that it was important for parents and their children to talk about sex at home. Parents in this study started talking about topics such as menarche, sexual abuse, and sexual intercourse at ages of 2, 5, 6, 7, and 8. Some of the parents reported that they spoke with their children about sexual topics because their own parents would not talk to them when they were children. One mother said

Because when we were little nobody told us about the stuff we know now. My mother would say," Go somewhere and sit down. " And I promised when I got older if there was something my kid needed to ask me about, I'm going to take the time to pay attention to it because it could be critical. I think parents should listen to their children more instead of being so quick to judge their children.

Adult participants said that parents were not talking to their children about sexuality because they were waiting for their children to initiate the conversations, and most children were afraid to do this. As one nurse practitioner said:

They [a group of mothers of teenagers] were like "well my daughter knows she can come to me" or "she knows about Planned Parenthood." They were just, in my mind, sort of ignorant to the reality of maybe your child isn't going to feel comfortable coming to you and talking to you about sex. Maybe they feel comfortable about everything else but [sex].

All the participants agreed that it was appropriate to teach sexuality in community settings such as schools and youth groups. Parents consistently reported that they valued sexuality education in the schools because it "broke the ice" and eased the initiation of the conversation at home. It also reinforced what the parents taught at home in a more "technical way."

Participants from all three groups believed that early sexuality education was important to prepare youths to protect themselves from premature or unwanted sexual activity. Some participants from all three groups identified that youths repeated sexual things that they heard without understanding what they were saying, thus sending messages that they had not intended. Early sexuality education was described as an ongoing, immediate way to counteract misinformation. Knowledge of sexual language and behaviors was suggested as a way to decrease vulnerability to sexual abuse as well as increase a child's ability to recognize and report abuse if it did occur.

\section{Recommended Education Content}

Haglund 6 
Participants from all three groups believed that sexuality education should be ongoing, with content increasing in sophistication as the child aged. Discussing risks at age-appropriate levels, when the risks were more likely to be encountered, would make the teaching more relevant. For example, most participants believed that discussing birth control and condoms at age 10 was appropriate but would be more meaningful if repeated at an older age when intercourse was more likely to occur. The participants said that the likelihood of having intercourse increased as youths became older adolescents. At the same time, they recognized that some initiated sexual intercourse during middle school. Providing education about safer sex to youths at age 10 would hopefully help them lower their risks at whatever age they started having sex.

Ongoing education would allow for opportunities to discuss more sophisticated topics and real-life situations such as cohabitation, unmarried parents with sexual partners, and homosexual couples. Participants from all three groups agreed that it was important to talk to young people about the risks associated with oral and anal intercourse and genital contact between persons of the same gender, but this information should be restricted until age 12 or older. As one 13-year-old girl said, "It is important to tell them about the risks because they might not know about risks and try it."

Participants from all three groups variously recommended that children in this age group should learn about puberty including body changes, hygiene, sperm production, ejaculation, and menarche as well as the physiology of sexual intercourse, including how pregnancies occur and how diseases are transmitted. The participants agreed that youths under 12 should be sent a clear message that they were too young to have sex. However, among respondents, the appropriate age for coitarche varied. Parents said that sex is for adults in a married or committed relationship; youths said that sex was for "older" people who were ready and responsible; and community members did not specify an age.

Teaching sexual vocabulary, scientific and slang, was recommended. Youths should be taught about sexual awakening including wet dreams and aspects of sexual arousal such as what arousal feels like, how to handle such feelings, and how arousal is different from love. Adult participants identified that some youthful sexual activity occurred because youths believed sexual myths such as arousal equated to feelings of love and that being in love meant one should have intercourse or that a boy could be physically hurt if he had an erection and did not subsequently have intercourse. The adults believed that correcting myths might prevent some sexual activity.

The adult participants recommended that sexuality education be about sexuality rather than focusing on specific sexual behaviors. Sexuality education should focus on interpersonal Haglund 7 
relationships and personal development. Youths need be taught to identify their values and how to make life choices consistent with those values. Community members suggested using a broad view of values in order to be respectful and inclusive of differences in culture and religion. Again, some participants from all three groups said that it was important to teach children how to respect and value themselves and others. Learning self-respect included how to set personal limits or boundaries and how to act, dress, and present oneself in a way that demonstrated dignity and inspired others to treat them respectfully. The adult participants believed that youths who dressed in sexually provocative clothing were tainting their self-image and presenting themselves as a target for sexual attention and possible danger. Respect for others included how to accept no, how to cultivate friendships, and how to treat others as you would like to be treated.

\section{Preferred Intervention Delivery Methods}

Talking to youths in a face-to-face format was the overwhelmingly preferred methodology for delivery of sexuality education. Participants from all three groups recommended allowing youths to ask questions about sexuality without restrictions. They believed strongly that it was important for youths to be listened to, to have their questions answered, and for adults to respond nonjudgmentally and without anger. For discussions in schools or community settings, the participants recommended small, same-gender groups. An anonymous question box was suggested as a way to allow youths to ask questions without feeling embarrassed.

Presentations. A variety of persons were identified as preferred presenters. An adolescent speaker would be beneficial as younger youths looked up to them and held them in positive regard. One teacher said

They're trying to visualize in their head right now what kind of teenager am I going to be. And I could see it with my son all the time because he sees people that he thinks are cool who are older and if he heard teenagers say things, and they ' $d$ say it in their language too, it would mean so much more than if the teachers said it.

Early adolescents may not interpret a teenager's advice as being told what to do, and the information may appear more relevant coming from a speaker with 1st-hand, current teenage experience.

An expert adult would also be a good presenter as they would have the knowledge to answer the children's questions and the youths could trust the accuracy of the information. A speaker who had had pertinent life experiences could provide a vicarious sense of how choices about sexuality may affect one's life. Other recommendations included creating an atmosphere in which participants felt comfortable asking questions and incorporating something lighthearted into the introduction to relieve some of the discomfort with discussing sexuality.

Haglund 8 
Parental Involvement. Participants from all three groups offered suggestions to get parents involved with sexuality education. Inviting parents to participate in a program with their children or having parent-only sessions may be ways to increase parental knowledge and stimulate parent-child dialogue. Sending home materials in advance for the parent to review may allow the parent to prepare their children before the program and also prepare the parent to answer questions after the program. Written materials or exercises for the parents and children to work on together at home as self-directed learning activities would also be beneficial.

Suggestions for obtaining parental permission for youths to attend sexuality education programs included allowing parents to preview materials, having the presenter speak to parents in advance, inviting parents to attend, and having a respected authority figure such as the school principal or a pastor advocate for the program. Some participants suggested statements to use when parents were hesitant to allow their child to participate in sexuality education. A 13-year-old suggested, "It may teach the kids something even the parents didn't know. " An idea from a 10-year-old was "Your kids might need to know about this stuff so when they get older they don't get a baby." One mother said, "If someone should try to influence the child to have sex, they wouldn't know if they should do it or not because no one taught them that it was wrong."

Activities. Participants recommended a variety of preferred activities in general. They also advocated for including a variety of activities in each program in order to appeal to different types of learners. Youths requested activities that they would enjoy." Make it fun for us while we were learning." They liked doing computer activities. They requested reading materials and workbooks so that kids might "figure it out by themselves." The youths valued both individual and group work. Suggestions for large groups included playing question and answer games, films, drama, and role-playing. Role-playing was an activity suited for practicing refusal skills, both saying and accepting no, and for teaching youths how to recognize and respond to peer pressure. Activities that encouraged youths to feel confident in their choice to be abstinent and to feel good about themselves were also recommended. As one 8-year-old participant said, youths should learn, "Don't try to be other than who you are."

\section{Discussion}

Experts have recommended that efforts to delay initiation of sexual intercourse might be most effective if offered to youths before they begin to have sex (Aarons et al., 2000; Aten et al., 2002). In this study, $84 \%$ of the participants believed that formal sexuality education should begin at ages 9 to 10. They believed that youths in this age group should hear a clear message that they Haglund 9 
were expected to abstain, yet participants agreed that they should still learn about safer sex measures. They did not believe that knowing how to practice safer sex would encourage youths to have intercourse. Rather, they believed that early knowledge would help most youths to avoid having sex and would protect those who did have sex early. Research evidence supports the premise that sexual education including teaching condom use may delay or decrease sexual activity rather than encouraging it. In one intervention study, early adolescents received safer sex, abstinence-only or general health education (control group) (Jemmott et al., 1998). Youths in the safer sex group, in which abstinence was promoted as the best choice, but condoms were emphasized for those who chose to have sex, reported less frequent intercourse and more frequent condom use than the control group and the abstinence-only group. In a 2nd study, high school students in the treatment group, which included abstinence skills and use of condoms, were less likely to initiate sexual intercourse than the control group immediately and 12 months after the intervention (St. Lawrence et al., 1995). Additionally, adolescents in schools where condom use was taught and condoms were available were less likely to report lifetime or recent sexual intercourse than in comparison schools (Blake et al., 2003).

This needs assessment does have limitations. The fi ndings are not generalizable because of the small, nonrepresentative, nonrandomized sample. In this study, parents, youths, and professionals largely agreed on the importance and appropriateness of sexuality education for school-age children. Opinions against comprehensive sexuality education were not elicited; thus, the range of opinion on this topic was not represented. Readers will have to judge the applicability of the findings to their own communities. Further research may include repeating this assessment with persons from different demographic backgrounds. Utilizing a research tool to assess the sexuality knowledge of youths would provide specific understanding of their knowledge and misunderstandings. Using a research tool with parents, youths, and professionals to assess belief in sexual myths might also be useful when planning education to counter erroneous information.

\section{Nursing Implications}

Nurses have a unique opportunity to dramatically affect the lives of young persons by providing them and their families with sexuality education. There are a variety of ways for nurses to provide sexuality education. Some nurses may incorporate the recommendations from this study into their group education programs. Other nurses, whose work with youths does not directly address sexuality, may develop creative ways to make talking about sexuality a regular part of their clinical practice. Nurses who work with adults may encourage them to initiate ongoing Haglund 10 
dialogues with the children in their lives.

Nurses may help youths by advocating for comprehensive sexuality education, rather than abstinence only, beginning in elementary school. Abstinence-only education programs have increased the knowledge of youths but have had little success in affecting their sexual behaviors (Aten et al., 2002; DiCenso, Guyatt, Willan, \& Griffi th, 2002). Sexuality education may be made more effective in altering behaviors if relationship issues rather than the mechanics of preventing a pregnancy or infection were emphasized and if sexuality were presented as part of a larger lesson on how to live as a healthy person whose choices are guided by values. Youths face serious consequences from sexual activity. It is imperative that nurses advocate for youths and help them to receive sexuality information in a timely, factual, and forthright manner.

\section{References}

Aarons, S., Jenkins, R., Raine, T., El-Khorazaty, M., Woodward, K., Williams, R., et al. (2000). Postponing sexual intercourse among urban junior high school students-a randomized controlled evaluation. Journal of Adolescent Health, 27, 236-247.

Aten, M., Siegel, D., Enaharo, M., \& Auinger, P. (2002). Keeping middle school students abstinent: Outcomes of a primary prevention intervention. Journal of Adolescent Health, 31, 70-78.

Blake, S., Ledsky, R., Goodenow, C., Sawyer, R., Lohrmann, D., \& Windsor, R. (2003). Condom availability programs in Massachusetts high schools: Relationships with condom use and sexual behavior. American Journal of Public Health, 93, 955-962.

Blake, S., Simkin, L., Ledsky, R., Perkins, C., \& Calabrese, J. (2001). Effects of a parent-child communications intervention on young adolescents' risk for early onset of sexual intercourse. Family Planning Perspectives, 33, 52-61.

Centers for Disease Control and Prevention. (2004). Diagnoses of HIV/AIDS-32 States, 2000-2003. Morbidity and Mortality Weekly Report, 53, 1106-1110.

Coyle, K., Kirby, D., Marlin, B., Gomez, C., \& Gregorich, S. (2003). Draw the line/respect the line: A randomized trial of a middle school intervention to reduce sexual risk behaviors. American Journal of Public Health, 94, 843-851.

DiCenso, A., Guyatt, G., Willan, A., \& Griffi th, L. (2002). Interventions to reduce unintended pregnancies among adolescents; systematic review of randomized controlled trials. British Medical Journal, 324, 1426-1430.

Grunbaum, J., Kann, L., Kinchen, S., Ross, J., Hawkins, J., Lowry, R., et al. (2004). Youth risk Haglund 11 
behavior surveillance - United States, 2003. Morbidity and Mortality Weekly Report, 53, 1-96.

Hamilton, B., Martin, J., \& Sutton, P. (2004). Births: Preliminary data for 2003. National Vital Statistics Reports, 53(9), 1-17.

Jemmott, J., Jemmott, L., \& Fong, G. (1998). Abstinence and safer sex HIV risk-reduction interventions for African American adolescents. JAMA, 279, 1529-1536.

Kirby, D., Korpi, M., Adivi, C., \& Weissman, J. (1997). An impact evaluation of project SNAPP: An AIDS and pregnancy prevention middle school program. AIDS Education and Prevention, 9(Suppl. A), 44-61.

Kirby, D., Korpi, M., Barth, R., \& Cagampang, H. (1997). The impact of the postponing sexual involvement curriculum among youths in California. Family Planning Perspectives, 29, 100-108.

Menacker, F., Martin, J., MacDorman, M., \& Ventura, S. (2004). Births to 10-14 year-old mothers 1990-2002. National Vital Statistics Reports, 53(7), 1-18.

Ozer, E., Brindis, C., Millstein, S., Knopf, D., \& Irwin, C. (1997). America's adolescents: Are they healthy? San Francisco: National Adolescent Health Information Center, University of California.

St. Lawrence, J., Brasfield, T., Jefferson, K., Alleyne, E., O’Brannon, R., \& Shirley, A. (1995). Cognitive-behavioral intervention to reduce African-American adolescents' risk for HIV infection. Journal of Consulting and Clinical Psychology, 63, 221-237.

Tiezzi, L., Lipshutz, J., Wrobleski, N., Vaughan, R., \& McCarthy, J. (1997). Pregnancy prevention among urban adolescents younger than 15: Results of the 'In Your Face ' program. Family Planning Perspectives, 29, 173-176 \& 197.

Ventura, S., Abma, J., Mosher, W., \& Henshaw, S. (2004). Estimated pregnancy rates for the United States, 1990-2000. National Vital Statistics Reports, 52(23), 1-9.

Haglund 12 


\section{Appendix}

Table 1

Description of Participants

\begin{tabular}{|c|c|c|c|}
\hline Character & Youths $^{\text {a }}$ & $\begin{array}{c}\text { Community } \\
\text { Members }\end{array}$ & Parent $^{\text {a }}$ \\
\hline Gender & & & 3 \\
\hline Male & 6 & 9 & 7 \\
\hline Female & 4 & 4 & 7 \\
\hline Ethnicity & 9 & 6 & 1 \\
\hline African American & 1 & 0 & 2 \\
\hline White & 0 & & 3 \\
\hline Hispanic & & & 4 \\
\hline $\begin{array}{l}\text { Family annual } \\
\text { income }\end{array}$ & 5 & & 2 \\
\hline$<\$ 10,000$ & 4 & & 1 \\
\hline$\$ 10,000-19,000$ & 0 & & \\
\hline$\$ 20,000-29,000$ & 1 & & \\
\hline$>\$ 50,000$ & & & \\
\hline
\end{tabular}

${ }^{a}$ Only five youths and four parents are from the same families.

${ }^{b}$ Ranges of $\$ 30,000$ to $\$ 50,000$ were omitted as no participants reported these categories.

Annual family income was obtained from parent after completion of informed consent. 


\section{Table 2}

\section{Interview Guide}

1. Do you think it is appropriate to talk to youths under 12 or between the ages of 10-12 about having sex and being sexually abstinent?

2. How do you define abstinence?

3. How much do you think youths in this age group know about sex and abstinence?

4. What do you teach your clients (or children) in this age group about sex and abstinence?

5. What do you think is the best way to teach youths about abstinence?

6. What types of things help children in this age group learn?

7. What content should be taught to youths in this age group?

8. Do you have any suggestions for how to handle community resistance to talking to youths ages 10-12 about sex?

9. Do you have any suggestions for how to handle parent resistance to talking to youths ages 10-12 about sex?

10. Do you have religious beliefs that influence your opinion on what you think youths should learn about sexuality? Tell me about them.

11 . Do you have any other comments or concerns? 